\title{
D-Aspartate Prevents Corticostriatal Long-Term Depression and Attenuates Schizophrenia-Like Symptoms Induced by Amphetamine and MK-801
}

\author{
Francesco Errico, ${ }^{1 \star}$ Silvia Rossi, ${ }^{2,3 \star}$ Francesco Napolitano, ${ }^{1}$ Valeria Catuogno, ${ }^{1}$ Enza Topo, ${ }^{4}$ Gilberto Fisone, ${ }^{5}$ \\ Antimo D'Aniello, ${ }^{4}$ Diego Centonze, ${ }^{2,3}$ and Alessandro Usiello ${ }^{1,6}$ \\ ${ }^{1}$ Laboratory of Behavioural Neuroscience, Centro Ingegneria Genetica Biotecnologie Avanzate, 80145 Naples, Italy, ${ }^{2}$ Clinica Neurologica, Università Tor \\ Vergata, 00133 Rome, Italy, ${ }^{3}$ Centro Europeo per la Ricerca sul Cervello/Fondazione Santa Lucia, 00179 Rome, Italy, ${ }^{4}$ Department of Neurobiology, Stazione \\ Zoologica “A. Dohrn," 80121 Naples, Italy, ${ }^{5}$ Department of Neuroscience, Karolinska Institutet, SE-171 77 Stockholm, Sweden, and ${ }^{6}$ Department of Health \\ Science, Università del Molise, 86100 Campobasso, Italy
}

\begin{abstract}
Since their discovery in the mammalian CNS, D-aspartate and D-serine have aroused a strong interest with regard to their role as putative neuromodulatory molecules. Whereas the functional role of D-serine as an endogenous coagonist of NMDA receptors (NMDARs) has been elucidated, the biological significance of D-aspartate in the brain is still mostly unclear. In the present study, we demonstrated that nonphysiological high levels of D-aspartate (1) increased in vivo NMDAR activity, (2) attenuated prepulse inhibition deficits induced by amphetamine and MK-801 [(+)-5-methyl-10,11-dihydro-5H-dibenzo[a,d]-cyclohepten-5,10-imine hydrogen maleate], (3) produced striatal adaptations of glutamate synapses resembling those observed after chronic haloperidol treatment, and (4) enhanced hippocampal NMDAR-dependent memory. This evidence was obtained using two different experimental strategies that produced an abnormal increase of endogenous D-aspartate levels in the mouse: a genetic approach based on the targeted deletion of the D-aspartate oxidase gene and a pharmacological approach based on oral administration of D-aspartate. This work provides in vivo evidence of a neuromodulatory role exerted by D-aspartate on NMDAR signaling and raises the intriguing hypothesis that also this D-amino acid, like D-serine, could be used as a therapeutic agent in the treatment of schizophrenia-related symptoms.
\end{abstract}

Key words: D-aspartate; NMDA receptors; schizophrenia; synaptic plasticity; prepulse inhibition; spatial memory; D-serine

\section{Introduction}

Schizophrenia (SCZ) is a severe mental disorder afflicting $\sim 1 \%$ of the population worldwide. Despite decades of intensive research, the precise etiology of this devastating mental illness remains, so far, an unresolved puzzle (Sawa and Snyder, 2002). It has been proposed that dysfunction of dopaminergic neurotransmission occurs in SCZ patients (Snyder, 1976); however, a large body of evidence recently proposed that abnormal serotonergic and glutamatergic neurotransmission might also be implicated in the pathophysiological processes leading to the development of schizophrenia (González-Maeso et al., 2008). Compelling evidence from genetic, brain imaging, and clinical studies strongly suggests that psychotic symptoms might be associated with a persistent hypoglutamatergic transmission involving reduced

Received Aug. 14, 2008; accepted Sept. 4, 2008.

D.C. was supported by the Italian Ministero dell'Università e della Ricerca (Fondo per gli Investimenti della Ricerca di Base 2006 grant) and by the Italian Ministero della Salute 2006 grant. A.U. represents Mariano Scippacercola Foundation. We thank S. Puglisi Allegra and C. Gross for helpful comments and discussions on this manuscript. We are also indebted to R. Romano, G. Piscopo, T. Pisapia, S. Esposito, and A. Di Camillo for their excellent technical assistance.

*F.E. and S.R. contributed equally to this work.

Correspondence should be addressed to Alessandro Usiello, CEINGE Biotecnologie Avanzate, Via Comunale Margherita 482, 80145 Naples, Italy. E-mail: usiello@ceinge.unina.it.

D0I:10.1523/JNEUROSCI.1618-08.2008

Copyright $\odot 2008$ Society for Neuroscience ～0270-6474/08/2810404-11\$15.00/0
NMDA receptor (NMDAR) activation (Tsai and Coyle, 2002). This hypothesis is mainly based on two fundamental observations: first, administration to healthy subjects of noncompetitive NMDAR antagonists, such as phencyclidine (PCP) or ketamine, results in severe mental symptoms resembling those of schizophrenic patients; second, administration of PCP to psychotic patients exacerbates positive and negative symptoms and worsens their cognitive functions (Javitt and Zukin, 1991; Olney and Farber, 1995). Together, these findings suggest that interventions able to enhance NMDAR transmission might be beneficial for the treatment of SCZ (Kristiansen et al., 2007). In particular, administration of D-serine to clozapine-treated patients ameliorates their positive, negative, and cognitive deficits (Tsai et al., 1999).

$\mathrm{D}$-Serine is a D-amino acid occurring in the mammalian forebrain throughout postnatal lifetime (Schell et al., 1995), which acts as an endogenous ligand at strychnine-insensitive glycinebinding site of NMDAR (Martineau et al., 2006). The striking discovery that D-serine could have therapeutic efficacy led to intensive investigations of the possible central functions of "unusual" free D-amino acids. Another D-amino acid, named D-aspartate, occurs in the mammalian brain. D-Aspartate levels are high in the embryonic phase and dramatically decrease during postnatal life, in concomitance with increased expression of D-aspartate oxidase (DDO), the enzyme responsible for its deg- 
radation (Schell et al., 1997; Errico et al., 2006; Huang et al., 2006). In contrast to D-serine, now well characterized for its implication in NMDAR-dependent functions, the role of $\mathrm{D}$-aspartate in the CNS remains elusive.

We have shown previously that D-aspartate enhances hippocampal NMDAR-dependent long-term potentiation (LTP) (Errico et al., 2008a). In the present work, we examined whether higher levels of this in-embryo-occurring molecule might increase glutamatergic transmission and exert antipsychotic effects in adult animals. Using genetic and pharmacological interventions able to enhance D-aspartate levels, we tested the ability of this D-amino acid to modulate cognition and gating abilities, which are thought, when altered, to be involved in the generation of SCZ-like symptoms. Furthermore, we investigated the ability of D-aspartate to modulate NMDAR-dependent electrophysiological responses and plasticity in the striatum, in an attempt to provide a physiological substrate for its action and putative antipsychotic-like effects.

\section{Materials and Methods}

Animals

Mutant mice for the Ddo gene were generated as described previously (Errico et al., 2006). Four-month-old male wild-type $\left(D d o^{+/+}\right)$and knock-out $\left(D d o^{-1-}\right)$ mice were used in this study and derived from mating of heterozygous $\left(D_{10}{ }^{+/-}\right)$mice, back-crossed to the F5 generation to C57BL/6J strain (Silva et al., 1997). Animals were genotyped by PCR according to Errico et al. (2006). C57BL/6J male mice were used to test the effects of 2 months of oral administration of D-aspartate in neurochemical, behavioral, biochemical, and electrophysiological studies. D-Aspartate was delivered in drinking water at the concentration of 20 $\mathrm{mm}$ to 45 -d-old mice until the age of $\sim 4$ months, when they were used for experiments. Although indistinguishable from untreated animals, D-aspartate-treated mice were slightly heavier than control counterparts $\left(\mathrm{H}_{2} \mathrm{O}\right.$ vs D-aspartate, $29.9 \pm 0.4 \mathrm{~g}$ vs $\left.32.4 \pm 0.4 \mathrm{~g} ; p<0.01\right)$

Mice were housed in groups $(n=4-5)$ in standard cages $(29 \times 17.5 \times$ $12.5 \mathrm{~cm})$ at a constant temperature $\left(22 \pm 1^{\circ} \mathrm{C}\right)$ and maintained on a $12 \mathrm{~h}$ light/dark cycle, with food and water ad libitum. Experiments were conducted in conformity with protocols approved by the veterinary department of the Italian Ministry of Health and in accordance with the ethical and safety rules and guidelines for the use of animals in biomedical research provided by the relevant Italian laws and European Union directives (n. 86/609/EC). All efforts were made to minimize the animals' suffering.

\section{HPLC analysis}

Four-month-old Ddo ${ }^{+/+}(n=5), \mathrm{Ddo}^{-1-}(n=5)$, and C57BL/6J mice that drank for 2 months $20 \mathrm{~mm} \mathrm{D}$-aspartate $(n=7)$ or $\mathrm{H}_{2} \mathrm{O}(n=7)$ were killed, and the striatum, cortex, hippocampus, and cerebellum were dissected and stored at $-80^{\circ} \mathrm{C}$. The determination of D-aspartate was performed by HPLC, based on the diastereomeric separation of D-aspartate from the L-form and other L-amino acids, as described previously (D'Aniello et al., 2000). Data were analyzed with a Student's $t$ test and expressed as means \pm SEM.

\section{Behavioral tests}

Acoustic startle response profile. Acoustic startle response (ASR) was measured using SR-Lab System (San Diego Instruments), according to a modified version of the protocol described by Paylor and Crawley (1997). Mice were gently handled $5 \mathrm{~min} / \mathrm{d}$ for 1 week before the experiment. Each test session began by placing a mouse in the Plexiglas cylinder, where it was left undisturbed for $5 \mathrm{~min}$ at the background noise level. After the acclimation period, each mouse was subjected to 40 trials. There were 10 different sound levels presented: $65,70,74,78,82,86,90,100$, 110 , and $120 \mathrm{~dB}$. Each stimulus lasted $40 \mathrm{~ms}$ and was presented four times in pseudorandom order such that each sound level was presented within a block of 10 trials. The average intertrial interval was $15 \mathrm{~s}$ (ranged from 10 to $20 \mathrm{~s}$ ). The startle response was recorded for $65 \mathrm{~ms}$ (measuring the response every $1 \mathrm{~ms}$ ) starting with the onset of the startle stimulus. The background noise level in each chamber was $65 \mathrm{~dB}$. The maximum startle amplitude recorded during the $65 \mathrm{~ms}$ sampling window was used as dependent variable. ASR was analyzed using two-way (genotype or treatment $\times$ startle stimulus levels) ANOVA with repeated measures.

Prepulse inhibition of the startle reflex. Prepulse inhibition (PPI) was measured using the SR-Lab System. The procedure was essentially as described previously (Errico et al., 2008b). Mice were gently handled 5 $\mathrm{min} / \mathrm{d}$ for 1 week before the experiment. A test session began by placing a mouse in the Plexiglas cylinder, where it was left undisturbed for $5 \mathrm{~min}$ at the background noise level. A test session consisted of eight trial types. One trial type was a $40 \mathrm{~ms}, 120 \mathrm{~dB}$ sound burst, used as the startle stimulus. There were six different acoustic prepulse plus acoustic startle stimulus trials. The prepulse sound was presented $100 \mathrm{~ms}$ before the startle stimulus. The $20 \mathrm{~ms}$ prepulse sounds were $70,74,78,82,86$, or 90 $\mathrm{dB}$. Finally, there were trials in which no stimulus was presented to measure baseline movements in the cylinder. Six blocks of the eight trial types were presented in a pseudorandom order such that each trial type was presented once within a block of seven trials. The average intertrial interval was $15 \mathrm{~s}$ (ranged from 10 to $20 \mathrm{~s}$ ). The startle response was recorded for $65 \mathrm{~ms}$ (measuring the response every $1 \mathrm{~ms}$ ) starting with the onset of the startle stimulus. The background noise level in each chamber was 65 $\mathrm{dB}$. The maximum startle amplitude recorded during the $65 \mathrm{~ms}$ sampling window was used as dependent variable. PPI was analyzed using two-way (genotype or treatment $\times$ prepulse sound levels) ANOVA with repeated measures. In challenge experiments with amphetamine sulfate (AMPH) (free base, 10 and $5 \mathrm{mg} / \mathrm{kg}$ ) and (+)-5-methyl-10,11-dihydro- $5 \mathrm{H}$ dibenzo $[a, d]$-cyclohepten-5,10-imine hydrogen maleate (MK-801) $(0.5$ and $0.25 \mathrm{mg} / \mathrm{kg}$ ), mice were assigned to receive either drug or vehicle (balanced for genotype or pretreatment and startle chamber assignment) and tested $5 \mathrm{~min}$ or $30 \mathrm{~min}$ after intraperitoneal injection, respectively. In these experiments, we chose to test only $70,74,78$, and $82 \mathrm{~dB}$ prepulse sound. PPI data were analyzed using three-way (genotype or pretreatment $\times$ drug treatment $\times$ prepulse sound levels) ANOVA with repeated measures.

Motor responses induced by AMPH or MK-801. The procedure was as described previously (Usiello et al., 2000). After $1 \mathrm{~h}$ of habituation to the test cage $(35 \times 25 \times 30 \mathrm{~cm}), \operatorname{AMPH}(0.5,1$, and $2.5 \mathrm{mg} / \mathrm{kg}), \mathrm{MK}-801$ $(0.05,0.1$, and $0.25 \mathrm{mg} / \mathrm{kg})$, or vehicle was injected to $D d o^{+/+}$and $\mathrm{Ddo}{ }^{-1-}$ mice 5 or $30 \mathrm{~min}$ before the beginning of the test session, respectively. Locomotion, expressed in centimeters, was recorded over $1 \mathrm{~h}$ by using a computerized video tracking system (Videotrack; Viewpoint). Motor responses to both drugs were evaluated by two-way (genotype $X$ treatment) ANOVA.

Morris water maze. The Morris water maze test was performed similarly to that described by Tang et al. (1999). The apparatus consisted of a circular pool (100 $\mathrm{cm}$ in diameter), surrounded by three-dimensional visual cues, containing opaque water at $21 \pm 1^{\circ} \mathrm{C}$ with a platform $(8 \mathrm{~cm}$ in diameter) submerged $1 \mathrm{~cm}$ beneath the water surface. Mice were gently handled $5 \mathrm{~min} / \mathrm{d}$ for 1 week before the experiment. The training phase consisted of two sessions per day ( $3 \mathrm{~h}$ interval between sessions) over a $5 \mathrm{~d}$ period. Each session was composed of four trials with an intertrial interval of $\sim 5 \mathrm{~min}$. The time to reach the target was measured. Two probe tests were performed along training, $24 \mathrm{~h}$ after the last session (to evaluate time-dependent memory retention of mice), in which animals were allowed to swim for $60 \mathrm{~s}$ in the absence of the platform. The first (probe 1) was done at day 4 , before the seventh session, whereas the second (probe 2 ) was conducted at the end of the training phase, at day 11 . The percentage of time spent in each quadrant was recorded. A computerized video tracking system (Videotrack; Viewpoint) was used for all Morris water maze tasks performed, to collect data during learning phase and probe tests. In the acquisition phase, the measure of the escape latency was used as dependent variable, and data were examined using two-way ANOVA (genotype or treatment $X$ days) with repeated measures. Data obtained in the probe trials were analyzed by Fischer's post hoc comparison, to evaluate the spatial preference of each experimental group for each quadrant. Moreover, Student's $t$ test was used to determine genotype effect on the spatial preference.

Contextual fear conditioning. Mice were gently handled $5 \mathrm{~min} / \mathrm{d}$ for 1 week before the experiment. On the training day, animals from the Ddo 
line $\left(D d o^{+/+}, n=18 ; D d o^{-/-}, n=17\right)$ or C57BL/6J mice $\left(\mathrm{H}_{2} \mathrm{O}\right.$-treated, $n=11$; D-aspartate-treated, $n=11$ ) were placed individually in a conditioning shock chamber (Freeze Monitor; San Diego Instruments) and tested according to a previously described protocol (Shumyatsky et al., 2002). Conditioning was assessed immediately and $24 \mathrm{~h}$ after training (retention session) by scoring freezing behavior, defined as the complete lack of movement (with the exception of respiratory movements). On testing day, contextual fear conditioning was evaluated and analyzed for $3 \mathrm{~min}$ in the context in which mice were trained. Both training and testing sessions were videotaped and analyzed ethologically for contextual freezing by an experimenter blind to the genotype or treatment. Student's $t$ test was used to determine genotype or treatment effect on the freezing behavior, expressed as percentage of time spent in freezing.

A significance level of $p<0.05$ was accepted as statistically significant in all the experiments performed. All measures are expressed as mean \pm SEM. All statistical analyses were performed with StatView software (version 5.0.1.0; SAS Institute).

Drugs. MK-801, AMPH, and D-aspartate were obtained from Sigma.

\section{Detection of cerebellar cGMP}

Cerebellar cGMP was measured under basal conditions in 4-month-old Ddo ${ }^{+/+}$and $D d o^{-1-}$ mice and in $\mathrm{H}_{2} \mathrm{O}$ - and D-aspartate-treated 4-month-old C57BL/6J animals according to the study by Wood et al. (1994). Moreover, cGMP was determined 20 or 40 min after intraperitoneal administration of $500 \mathrm{mg} / \mathrm{kg}$ D-aspartate or vehicle to C57BL/6J mice. Animals were killed by decapitation, the brains were then removed, and the cerebella were dissected out on an ice-cold surface and stored at $-80^{\circ} \mathrm{C}$. Frozen cerebella were ground to a fine powder using dry-icecooled stainless-steel pestle and mortar. Powder was then homogenized in 10 volumes of $0.1 \mathrm{M} \mathrm{HCl}$. After the addition of $4 \mathrm{~m}$ TCA and centrifugation at $10,000 \mathrm{rpm}$ for $10 \mathrm{~min}$ at $4^{\circ} \mathrm{C}$, supernatants were analyzed for cGMP by radioimmunoassay (GE Healthcare).

\section{Electrophysiology}

Male $D d o^{-1-}$ mice and mice chronically treated with D-aspartate (2 months) were used along with their respective controls for the electrophysiological experiments. All the experiments were performed in accordance with the European Communities Council Directive (86/609/EEC) and with approval of the Institutional Animal Care and Use Committee of the University of Tor Vergata. Vibratome-cut coronal corticostriatal slices $(200-300 \mu \mathrm{m})$ from the dorsal striatum were prepared for electrophysiological recordings as described previously (Centonze et al., 2004a) and then transferred to a recording chamber submerged in a continuously flowing artificial CSF (ACSF) $\left(33^{\circ} \mathrm{C}, 2-3 \mathrm{ml} / \mathrm{min}\right.$ ) gassed with $95 \%$ $\mathrm{O}_{2}-5 \% \mathrm{CO}_{2}$. The composition of the control solution was (in $\mathrm{mM}$ ) 126 $\mathrm{NaCl}, 2.5 \mathrm{KCl}, 1.2 \mathrm{MgCl}_{2}, 1.2 \mathrm{NaH}_{2} \mathrm{PO}_{4}, 2.4 \mathrm{CaCl}_{2}, 11$ glucose, and 25 $\mathrm{NaHCO}_{3}$.

Experiments aimed at investigating the effects of D-aspartate application (Sigma) on the membrane properties of striatal neurons were performed in whole-cell patch clamp. Whole-cell patch-clamp recordings from single striatal principal neurons were also obtained to study spontaneous EPSCs (sEPSCs).

Individual neurons were visualized in situ using a differential interference contrast (Nomarski) optical system. This used an Olympus BX50WI upright microscope with $40 \times$ water-immersion objective combined with an infrared filter, a monochrome CCD camera (COHU 4912), and a PC-compatible system for analysis of images and contrast enhancement (WinVision 2000; Delta Sistemi). Recording pipettes were advanced toward individual striatal cells in the slice under positive pressure and, on contact, tight gigaohm seals were made by applying negative pressure. The membrane patch was then ruptured by suction, and membrane current and potential were monitored using an Axopatch 1D patch-clamp amplifier (Molecular Devices). Whole-cell access resistances measured in voltage clamp were in the range of 5-20 M $\Omega$.

Whole-cell patch-clamp recordings were made with borosilicate glass pipettes (1.8 mm o.d.; $2-4 \mathrm{M} \Omega$ ). The recording pipettes were filled with internal solution of the following composition (mM): $125 \mathrm{~K}^{+}$-gluconate, $10 \mathrm{NaCl}, \quad 1.0 \quad \mathrm{CaCl}_{2}, \quad 2.0 \quad \mathrm{MgCl}_{2}, \quad 0.5$ 1,2-bis(2-aminophenoxy) ethane- $N, N, N, N$-tetra-acetic acid (BAPTA), 19 HEPES, 0.3 GTP, and
1.0 Mg-ATP, adjusted to $\mathrm{pH} 7.3$ with $\mathrm{KOH}$. Bicuculline $(10 \mu \mathrm{M})$ was added to the perfusing solution to block $\mathrm{GABA}_{\mathrm{A}}$-mediated transmission. All synaptic events were recorded at the holding potential of $-80 \mathrm{mV}$ and stored by using P-CLAMP 9 (Molecular Devices).

Spontaneous excitatory currents were analyzed off-line on a personal computer with Mini Analysis 5.1 (Synaptosoft) software. The detection threshold of these events was set at twice the baseline noise. The fact that no false events would be identified was confirmed by visual inspection for each experiment. Off-line analysis was performed on spontaneous synaptic events recorded during a fixed time epoch (1-3 min), sampled every 2 or 3 min for a total of $\sim 15-20$ samplings. Only cells that exhibited stable frequencies ( $<20 \%$ changes during the samplings) were taken into account. For kinetic analysis, events with peak amplitude between 10 and $50 \mathrm{pA}$ were grouped, aligned by half-rise time, and normalized by peak amplitude. Events with complex peaks were eliminated. In each cell, all events between 10 and $50 \mathrm{pA}$ were averaged to obtain rise times, decay times, and half-widths.

Corticostriatal long-term depression (LTD) was studied by means of intracellular recordings. Intracellular recording electrodes were filled with $2 \mathrm{M} \mathrm{KCl}$ (tip resistance of 30-60 M $\Omega$ ). Signals were recorded using an Axoclamp 2A amplifier, displayed on a separate oscilloscope, and stored and analyzed on a digital system (pClamp 8; Molecular Devices). For synaptic stimulation, bipolar electrodes were used. They were located in the white matter between the cortex and the striatum to activate corticostriatal fibers. EPSPs were evoked at $0.1 \mathrm{~Hz}$. Bicuculline was added to block $\mathrm{GABA}_{\mathrm{A}}$-mediated transmission. Under this experimental condition, high-frequency stimulation (HFS) of corticostriatal fibers ( 3 trains, $3 \mathrm{~s}$ duration, $100 \mathrm{~Hz}$ frequency, $20 \mathrm{~s}$ interval) was used as an LTDinducing protocol (Calabresi et al., 1992). Quantitative data on modifications of EPSPs are expressed as percentage of the controls, the latter representing the mean of responses recorded during a stable period (5-10 min) before the repetitive HFS synaptic stimulation.

Only one cell per slice and less than five neurons per animal were recorded. For data presented as the mean \pm SEM, statistical analysis was performed using a paired or unpaired Student's $t$ test or Wilcoxon's test. The significance level was established at $p<0.05$. To determine whether two cumulative distributions of spontaneous synaptic activity were significantly different, the Kolmogorov-Smirnov test was used.

Drugs used for the electrophysiological experiments were applied by dissolving them to the desired final concentration in the bathing ACSF. APV, CNQX, NMDA, and MK-801 were purchased from Tocris Bioscience). Bicuculline was from Sigma/RBI.

\section{Western blotting}

Four-month-old Ddo ${ }^{+/+}(n=10)$ and Ddo ${ }^{-1-}(n=10)$ and C57BL/6J mice that drank for 2 months $20 \mathrm{~mm}$ D-aspartate $(n=6)$ or $\mathrm{H}_{2} \mathrm{O}(n=6)$ were killed, and the striatum was dissected out, sonicated in $200 \mu \mathrm{l}$ of $1 \%$ SDS, and boiled for $10 \mathrm{~min}$. Aliquots $(2 \mu \mathrm{l})$ of the homogenate were used for protein determination using a Bio-Rad Protein Assay kit. Equal amounts of total proteins $(30 \mu \mathrm{g}$ ) for each sample were loaded onto $10 \%$ polyacrylamide gels. Proteins were separated by SDS-PAGE and transferred overnight to membranes (polyvinylidene difluoride) (GE Healthcare). The membranes were immunoblotted using selective antibodies against NR1 (1:1000; Sigma), NR2A (1:1000; Sigma), NR2B (1:1000; Millipore), GluR1 (1:5000; Millipore Bioscience Research Reagents), GluR2/3 (1:1000; Millipore), and DARPP32 (1:1000; Cell Signaling Technology). Blots were then incubated in horseradish peroxidaseconjugated secondary antibodies, and target proteins were visualized by ECL detection (Pierce), followed by imaging using a Bio-Rad Chemidoc instrument with quantitation by Quantity One software (Bio-Rad). Optical density values were normalized to DARPP32 for variations in loading and transfer. Normalized values were then averaged and used for statistical comparisons (Student's $t$ test).

\section{Results}

High levels of D-aspartate in discrete brain regions of $\mathrm{Ddo}^{-/-}$ and 2 month chronically treated mice

Recently, two independent laboratories have demonstrated that ablation of the Ddo gene, obtained by genetic homologous re- 

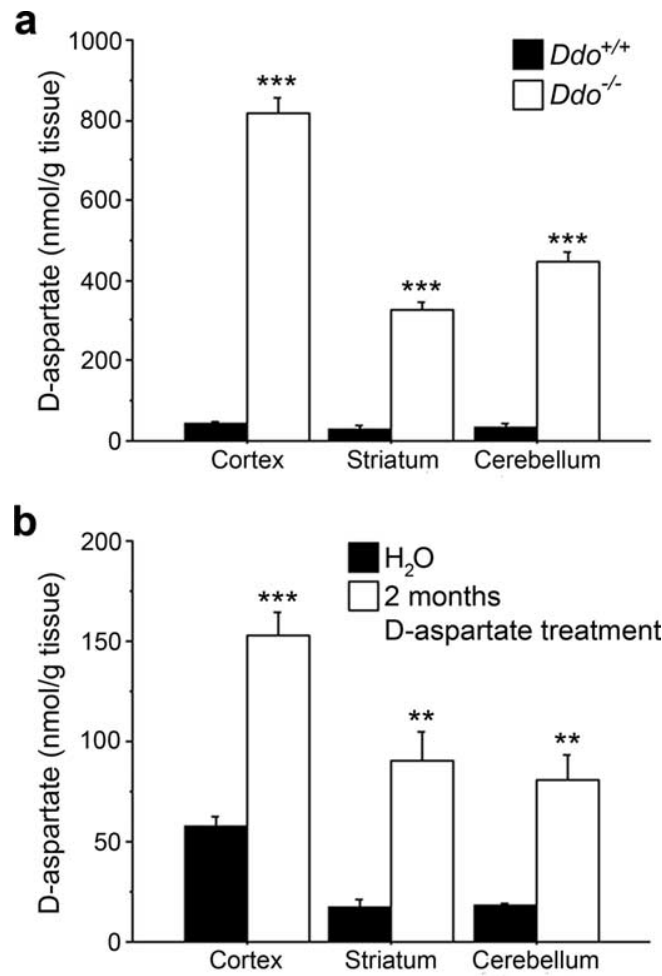

Figure 1. Altered high levels of $D$-aspartate in discrete brain regions of $D d 0^{-1-}$ and 2 month D-aspartate-treated C57BL/6J mice. $\boldsymbol{a}, \boldsymbol{b}, \mathrm{D}$-Aspartate levels were measured by HPLC in the cortex, striatum, and cerebellum of 4-month-old Ddo ${ }^{+/+}(n=5)$ and Ddo ${ }^{-1-}(n=5)$ mice $(\boldsymbol{a})$ and 4-month-old 57BL/6J mice, untreated $(n=7)$ or treated with D-aspartate $(n=$ 7) (b). Treated animals drank a $20 \mathrm{~mm}$ D-aspartate solution for 2 months before HPLC detection. ${ }^{* *} p<0.01,{ }^{* * *} p<0.0001$, compared with control groups. Values are expressed as mean \pm SEM. Genotypes and treatments are as indicated.

combination, results in a substantial increase of $\mathrm{D}$-aspartate levels in adult mutant mice (Errico et al., 2006; Huang et al., 2006). These data, observed both in endocrine glands and in the brain, clearly demonstrated a pivotal role for DDO in controlling the physiological content of D-aspartate in mammals. In addition, Errico et al. (2008a) showed that 1 month of chronic oral administration of $\mathrm{D}$-aspartate to $\mathrm{C} 57 \mathrm{BL} / 6 \mathrm{~J}$ mice produced a significant increase in the levels of this D-amino acid in the hippocampus. Herein, we have extended the analysis of D-aspartate content to other brain regions such as the cortex, striatum, and cerebellum, in $D d o^{-1-}$ animals and in C57BL/6J mice treated for 2 months with D-aspartate.

HPLC measurements indicated that D-aspartate levels were abnormally higher in all tested brain regions, both in genetic (Fig. $1 a$ ) and pharmacological (Fig. $1 b$ ) animal models, compared with their specific control groups. Indeed, statistical analyses indicated a significant genotype effect $(p<0.0001$, per each brain region) and a $\mathrm{D}$-aspartate chronic treatment effect $(p<0.0001$, per cortex; $p<0.01$, per striatum and cerebellum).

\section{ASR and PPI are unaltered after elevation of D-aspartate levels}

One of the widely used cross-species behavioral paradigms to measure sensorimotor gating, commonly altered in schizophrenic patients, is the PPI of the startle response (Swerdlow et al., 2000; Braff et al., 2001). PPI occurs when a low-intensity prepulse precedes a startle stimulus, resulting in a reduced startle response. PPI is primarily based on the sensory detection of stimulus; therefore, an evaluation of this filtering mechanism requires that animals do not show any hearing or startle reflex impairment. Thus, to assess whether deregulated D-aspartate levels resulted in sensory or startle disturbance, we first tested ASR in 4-month-old Ddo ${ }^{-1-}$ and D-aspartate-treated C57BL/6J mice. We showed that startle amplitude did not differ between knockout and wild-type animals, at each tone intensity tested (Fig. 2a). In fact, statistical analysis indicated a nonsignificant (n.s.) genotype effect (ANOVA, $p>0.1$ ) and n.s. interaction between genotype and decibel levels (ANOVA, $p>0.1$ ). Similarly, no difference in ASR occurred between chronically treated mice and control group (Fig. $2 b$ ), as indicated by the absence of D-aspartate pretreatment effect (ANOVA, $p>0.1$ ) as well as by an n.s. interaction between pretreatment and decibel levels (ANOVA, $p>$ 0.1 ). Then, we analyzed both animal models for their PPI baseline. Our data indicated that PPI was indistinguishable between genotypes, at all prepulse levels tested (Fig. $2 c$ ). Indeed, there was no difference between $D d o^{-1-}$ and $D d o^{+/+}$littermates (ANOVA, $p>$ 0.1 ) and no interaction between genotype and prepulse decibel levels (ANOVA, $p>0.1$ ). In addition, no statistical difference was found in basal PPI responses between D-aspartate-pretreated mice and control group (ANOVA, $p>0.1$ ), and an n.s. interaction effect was observed between pretreatment and prepulse decibel levels $($ ANOVA, $p>0.1$ ) (Fig. $2 d$ )

\section{D-Aspartate elevation attenuates the disruptive effects of AMPH and MK-801 on PPI of startle reflex}

It is well established that AMPH, a potent dopamine releaser, induces PPI deficits in humans and rodents, most likely through its aberrant stimulation of dopaminergic transmission (Mansbach et al., 1988; Braff et al., 1992). To investigate the functional consequences of high brain levels of D-aspartate in AMPHinduced PPI deficits, $D d o^{-1-}$ and $D d o^{+/+}$mice were treated with this psychostimulant, at the dose of $5 \mathrm{mg} / \mathrm{kg}$ (Fig. $3 a$ ). A significant attenuation of AMPH-induced disruption of PPI was found in Ddo knock-out mice. Indeed, statistical analysis showed a main effect of genotype (ANOVA, $p<0.05$ ) and, more relevant, a significant interaction between AMPH and genotype (ANOVA, $p<0.05)$. Interestingly, AMPH significantly lowered PPI in $D d o^{+/+}$mice, at each tone intensity tested (ANOVA, $p<0.01$ ), but such PPI disruptive effect was absent in mice lacking the DDO enzyme (ANOVA, $p>0.1$ ). Conversely, when tested for its motor stimulant properties, AMPH induced comparable effects between genotypes, as indicated by n.s. main effect of genotype (ANOVA, $p>0.1$ ) and n.s. interaction between genotype and doses (ANOVA, $p>0.1$ ) (supplemental Fig. S1a, available at www.jneurosci.org as supplemental material). To explore whether D-aspartate oral administration produced a similar protective effect on sensorimotor gating disruption, we challenged treated C57BL/6J mice and their controls with AMPH (5 mg/kg). Similarly to Ddo knock-out mice, D-aspartate-treated animals also displayed a significant reduction in PPI deficit (Fig. 3b). Statistical analysis indicated a main effect of AMPH (ANOVA, $p<0.0001)$. However, whereas in C57BL/6J control mice this drug significantly lowered inhibition at each tone intensity tested (ANOVA, $p<0.01$ ), in D-aspartate-pretreated mice we found a blunted AMPH effect (ANOVA, $p>0.05$ ).

Similarly to AMPH, blockade of NMDAR also results in severe sensorimotor gating deficits (Curzon and Decker, 1998). Therefore, we investigated the effects of D-aspartate on MK-801induced disruption of PPI. Pharmacological blockade of NMDAR with MK-801 $(0.25 \mathrm{mg} / \mathrm{kg})$ induced a PPI deficit in both $D d o^{-1-}$ and $D d o^{+/+}$siblings, as indicated by a significant treatment effect (ANOVA, $p<0.0001$ ). However, a significant inter- 
action between MK-801 and genotype was detected (ANOVA, $p<0.01$ ), because in knock-out mice these effects were less pronounced than those occurring in wild-type littermates (ANOVA: treatment effect, Ddo $\left.{ }^{+/+}, p<0.0001 ; D d o^{-/-}, p<0.05\right)$ (Fig. $3 c$ ). In addition, we also analyzed the motor stimulant properties of MK-801 administration in $D d o^{-1-}$ and $D d o^{+/+}$mice. Interestingly, the results indicated a comparable motor stimulation in both genotypes, as indicated by a significant MK-801 effect (ANOVA, $p<0.0001$ ), n.s. effect of genotype (ANOVA, $p>0.1$ ), and n.s. interaction between genotype and doses (ANOVA, $p>0.1$ ) (supplemental Fig. $\mathrm{S} 1 b$, available at www.jneurosci.org as supplemental material). In contrast, MK801 induced a significant disruption of PPI in C57BL/6J untreated animals (ANOVA, $p<0.05)$, whereas in $\mathrm{D}$-aspartate-treated mice, the dose of $0.25 \mathrm{mg} / \mathrm{kg}$ did not produce any detectable deficit (ANOVA, $p>$ 0.1 ) (Fig. 3d).

Furthermore, to establish the extent of the protective properties of $\mathrm{D}$-aspartate on sensorimotor gating deficits, we tested higher doses of AMPH and MK-801 (10 $\mathrm{mg} / \mathrm{kg}$ and $0.5 \mathrm{mg} / \mathrm{kg}$, respectively). Interestingly, at these concentrations, a comparable disruption of PPI was found, regardless of genotype, for both AMPH (ANOVA, genotype effect and genotype $\times$ AMPH interaction, $p>0.1$ ) (supplemental Fig. S2 $a$, available at www.jneurosci.org as supplemental material) and MK-801 (ANOVA, genotype effect and genotype $\times$ MK-801 interaction, $p>0.1$ ) (supplemental Fig. S2c, available at www.jneurosci.org as supplemental material). Similarly, comparable PPI deficits were found between control and D-aspartate-pretreated mice, both with AMPH (ANOVA, pretreatment effect and pretreatment $\times$ AMPH interaction, $p>$ 0.1) (supplemental Fig. S2 $b$, available at www.jneurosci.org as supplemental material) and MK-801 (ANOVA, pretreatment effect and pretreatment $\times$ MK-801 interaction, $p>0.1$ ) (supplemental Fig. S2 $d$, available at www.jneurosci.org as supplemental material).

Finally, we analyzed AMPH and MK-801 effects on ASR in both Ddo mutants and D-aspartate-treated mice. Overall, our results indicated no main differences between genotypes and D-aspartate treatment in ASR effects induced by AMPH (ANOVA: genotype effect and genotype $\times$ AMPH interaction, $p>0.1$; pretreatment effect and pretreatment $\times$ AMPH interaction, $p>0.1$ ) (supplemental Fig. S3a,b, available at www. jneurosci.org as supplemental material) and MK-801 (ANOVA: genotype effect, $p>0.1$ and genotype $\times$ MK- 801 interaction, $p>$ 0.1 ; pretreatment effect and pretreatment $\times$ MK- 801 interaction, $p>0.1$ ) (supplemental Fig. S3c,d, available at www.jneurosci.org as supplemental material).

\section{D-Aspartate increases NMDAR activity}

We investigated the physiological effects of D-aspartate in the striatum, a brain area involved in cognitive and motivational functions, which are altered in SCZ (Goldman-Rakic and Selemon, 1990; Graybiel, 1997; Canales and Graybiel, 2000). Application of D-aspartate $(0.1,0.3$, and $1 \mathrm{~mm}, 30 \mathrm{~s})$ produced a dose-dependent inward current in striatal neurons recorded from control mice ( $n=$ at least $5 ; p<0.01$ for the three doses) (Fig. 4a). This effect was reversible at the wash of this D-amino acid and mostly blocked by MK-801 (30 $\mu \mathrm{M})$ or APV $(50 \mu \mathrm{M})$, noncompetitive and competitive antagonists of NMDARs, respectively ( $n=5$ for both antagonists; $p<0.01$ vs predrug values and $p<0.05$ vs D-aspartate alone) (Fig. $4 b$ ). However, even in the presence of these antagonists, D-aspartate was still able to excite striatal neurons, possibly because of the stimulation of APV- and MK-801-insensitive ionotropic receptors. The ability of both MK-801 and APV to fully block NMDARs was tested in a further set of experiments after the application of NMDA. As shown in Figure $4 c$, NMDA induced inward currents in striatal neurons $(n=11 ; p<0.001)$ that were fully antagonized by MK-801 $(n=$ $5)$ or APV $(n=5)$ ( $p>0.05$ vs predrug values and $p<0.001$ vs NMDA alone). Neither D-aspartate $(n=5)$ nor NMDA responses $(n=4)$ were affected by CNQX $(10 \mu \mathrm{M})$, an antagonist of glutamate AMPARs $(p>0.05$ compared with D-aspartate or NMDA alone) (Fig. $4 d$ ).

To further scrutinize D-aspartate effects on NMDARs, we also studied the in vivo changes in their activity evoked by persistent deregulation of this D-amino acid or by its acute administration. According to Wood et al. (1994), we used cerebellar cGMP assay as a reliable in vivo index of NMDAR activity. In this regard, we evaluated cerebellar cGMP levels 20 or $40 \mathrm{~min}$ after D-aspartate $(500 \mathrm{mg} / \mathrm{kg}$ ) acute challenge and in chronically treated and Ddo ${ }^{-1-}$ animals. Consistent with the idea that D-aspartate modulates NMDAR function, we observed that acute administration of D-aspartate induced a significant increase in cerebellar cGMP levels, compared with vehicle-treated group (ANOVA, treatment effect, $p<0.0001$ ) (Fig. 4e). The specific effect observed in acute $\mathrm{D}$-aspartate-treated mice occurred exclusively at $40 \mathrm{~min}$, but not at $20 \mathrm{~min}$, indicating a time-dependent requirement for this D-amino acid to trigger NMDAR stimulation effect (ANOVA, 
a

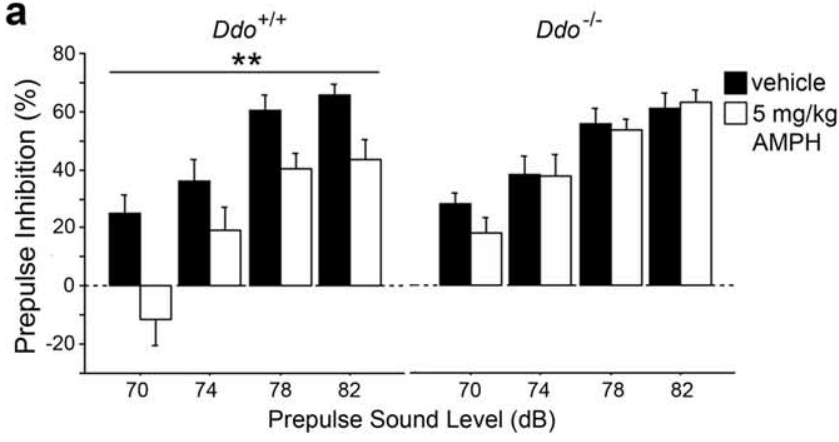

b

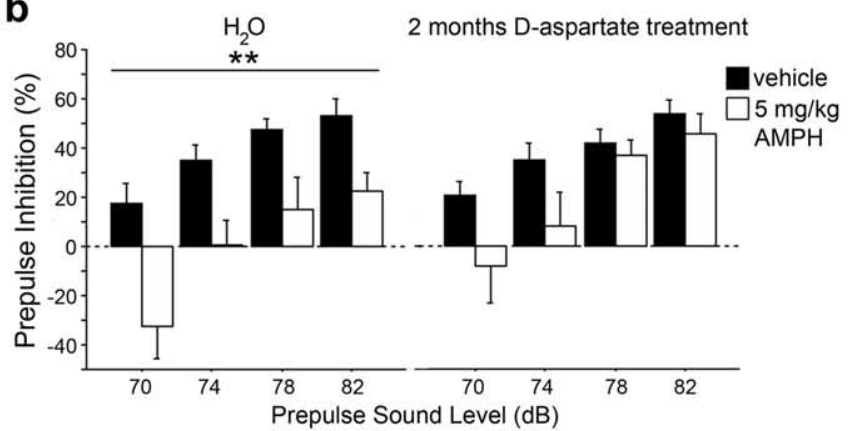

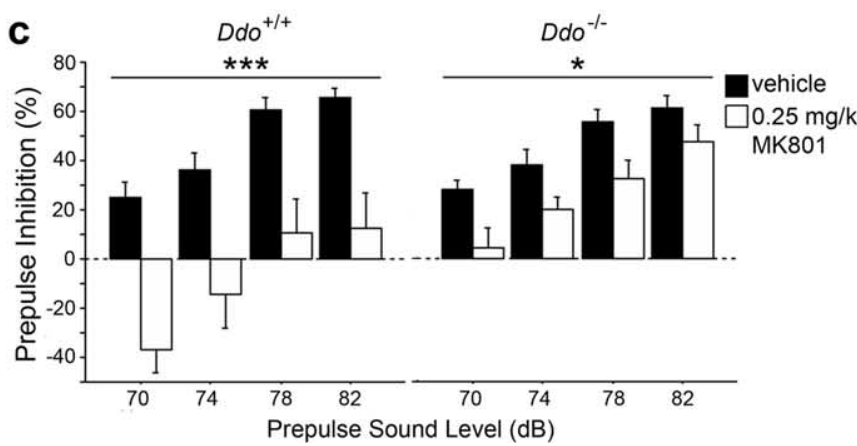

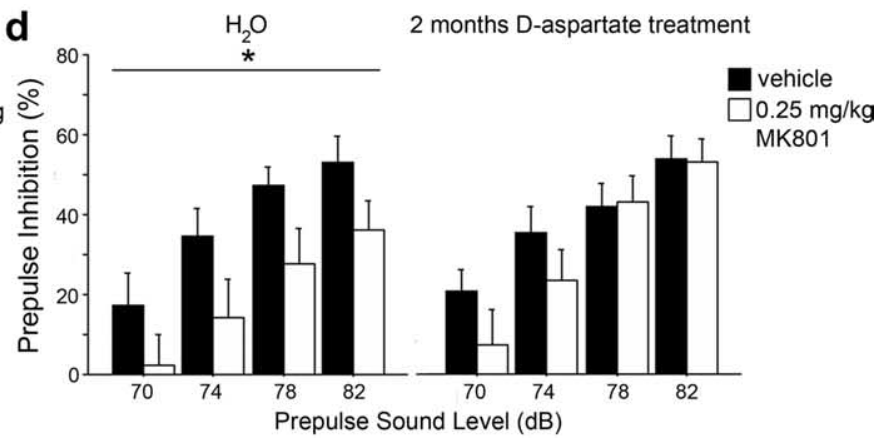

Figure 3. $D d 0^{-1-}$ and D-aspartate chronically treated mice display attenuated AMPH and MK-801 disruptive effects in PPI. $\boldsymbol{a}$, The dopamine releaser AMPH (5 mg/kg) induced a significant decrease in PPI of $D d 0^{+/+}$mice (vehicle, $n=20 ; \mathrm{AMPH}, n=17$ ) but did not affect the inhibitory responses of their $D$ do ${ }^{-/-}$littermates (vehicle, $n=20 ;$ AMPH, $n=17$ ). $\boldsymbol{b}$, Likewise, the same

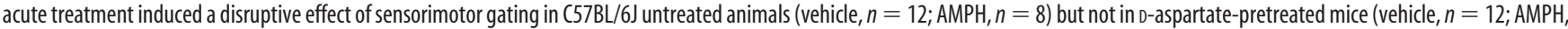
$n=8$ ). c, Differently from AMPH, the noncompetitive NMDAR antagonist MK-801, at the dose of $0.25 \mathrm{mg} / \mathrm{kg}$, produced a deficit in PPI in both Ddo $+/+($ vehicle, $n=20 ;$ MK-801, $n=8$ ) and $D_{d o}{ }^{-1-}$ (vehicle, $n=20$; MK-801, $n=8$ ) mice, although it was more pronounced in wild-type animals. $\boldsymbol{d}$, In the pharmacological animal model, the same dose of MK-801 was effective in $\mathrm{H}_{2} 0$-treated $\mathrm{C57BL} / 6 \mathrm{~J}$ mice (vehicle, $n=12 ;$ MK-801, $n=10$ ) but failed to produce deficits in their D-aspartate-treated littermates (vehicle, $n=12 ;$ MK-801, $n=10$ ). Percentage of the PPI was used as dependent variable. ${ }^{*} p<0.05,{ }^{* *} p<0.01,{ }^{* * *} p<0.0001$, compared with vehicle control groups (2-way ANOVA). All values are expressed as the mean \pm SEM. Genotypes and treatments are as indicated.

time effect, $p<0.0001)$. Similarly, chronic D-aspartate administration caused in treated animals a higher basal state of NMDAR activity, as indicated by the significant increase of cGMP, compared with the levels observed in control group $\left(\mathrm{H}_{2} \mathrm{O}\right.$ vs D-aspartate, $339.0 \pm 8.9$ vs $425.2 \pm 29.2 \mathrm{pmol} / \mathrm{g}$ tissue; $p<0.05$, Student's $t$ test). Interestingly, despite the highest content of D-aspartate in $D d o^{-1-}$ brains, compared with that observed in treated mice, cGMP levels did not differ from those measured in the cerebellum of wild-type animals $\left(D d o^{+/+}\right.$vs $D d o^{-/-}$, $345.0 \pm 17.3$ vs $351.7 \pm 26.0 \mathrm{pmol} / \mathrm{g}$ tissue; $p>0.1)$.

\section{Altered corticostriatal synaptic transmission and plasticity in Ddo $^{-1-}$ and D-aspartate-treated mice}

The effects of D-aspartate on striatal glutamate transmission were also investigated in $\mathrm{Ddo} \mathrm{o}^{-/-}$mice and in mice receiving $\mathrm{D}$-aspartate in their drinking solution. In current-clamp intracellular recordings, resting membrane potential and input resistance of striatal neurons were similar $(p>0.05)$ in control animals $(n=11)$ and in $D d o^{-/-}(n=10)$ and chronic D-aspartate-treated mice $(n=12)$, and ranged between -80 and $-86 \mathrm{mV}$ and 42 and $64 \mathrm{M} \Omega$, respectively $(n=$ at least 10 neurons for each group). Striatal cells were silent at rest and showed membrane rectification and tonic firing activity during depolarizing current pulses. These features closely resembled the electrical activity described previously for mouse spiny neurons (Centonze et al., 2004a). We focused our attention on the potential effect of D-aspartate on corticostriatal LTD, because this form of synaptic plasticity is blocked after enhancement of NMDAR signaling (Calabresi et al., 1992), as well as in response to antipsychotic treatment with haloperidol (Centonze et al., 2004a). Accordingly, corticostriatal LTD was absent in both $D d o^{-/-}$mice $(n=9 ; p>$ $0.05)$ and mice chronically treated with $\mathrm{D}$-aspartate $(n=8 ; p>$ $0.05)$, whereas it was normally expressed in the relative control groups ( $n=8$ and $p<0.01$ for both groups) (Fig. $5 a$ ).

Moreover, we evaluated the properties of sEPSCs after D-aspartate elevation. sEPSC frequency, in fact, is typically altered after inactivation of dopamine $\mathrm{D}_{2}$ Rs (Cepeda et al., 2001; Tang et al., 2001; Centonze et al., 2004b), which is also known to prevent PPI disruption by AMPH (Ralph et al., 1999). In Ddo ${ }^{-/-}$ mice ( $n=15$ cells), the frequency of striatal sEPSCs was higher than in control animals $(n=13$ cells; $p<0.01)$, thereby mimicking the effect of $\mathrm{D}_{2} \mathrm{R}$ blockade on this physiological parameter. Amplitude and kinetic properties of sEPSCs were conversely unaffected by $D d o$ gene ablation $\left(n=15\right.$ for $D d o^{-/-}$mice; $n=13$ for $D d o^{+/+}$mice; $p>0.05$ for each electrophysiological parameter). However, sEPSCs were unchanged in mice treated chronically with D-aspartate $(n=$ at least 10 cells for each experimental group; $p>0.05$ ), suggesting that $D d o$ genetic inactivation since early developmental stages might trigger this neuroadaptive process (Fig. 5b).

In light of the changes of glutamate transmission seen in Ddo ${ }^{-/-}$and D-aspartate-treated mice, we then analyzed whether nonphysiological levels of D-aspartate might affect the expression of NMDAR and/or AMPAR subunits within their striatum. Overall, Western blotting analysis revealed a comparable expression between genotypes for each NMDAR and AMPAR subunit ( $p>0.1$, per each protein) (Fig. $5 c, d$, respectively). Likewise, both striatal NMDAR and AMPAR subunit levels were unaf- 
fected by D-aspartate chronic treatment ( $p>0.1$, per each protein) (Fig. 5e,f, respectively).

\section{Improved hippocampus-dependent memory in Ddo ${ }^{-1-}$ mice}

It is established that NMDAR signaling plays a pivotal role in hippocampusrelated learning and memory (Lynch, 2004). Thus, based on the ability of D-aspartate to act as NMDAR agonist, we studied $\mathrm{Ddo}^{-1-}$ and D-aspartate chronically treated animals, displaying exacerbated hippocampal levels of this D-amino acid $\left(D d o^{+1+}\right.$ vs $D d o^{-1-}, 33.8 \pm 4.0$ vs $408.0 \pm 26.7 \mathrm{nmol} / \mathrm{g}$ tissue, $p<0.0001$; $\mathrm{H}_{2} \mathrm{O}$ vs D-aspartate, $35.2 \pm 3.2$ vs $133.6 \pm$ $9.5 \mathrm{nmol} / \mathrm{g}$ tissue, $p<0.0001$; Student's $t$ test), in a hidden platform version of the Morris water maze and in a contextdependent fear conditioning paradigm.

In the Morris maze test, we found unaltered spatial learning abilities in $D d o^{-1-}$ and D-aspartate chronically treated mice (Fig. $6 a, d)$. Indeed, statistical analysis did not reveal significant differences in spatial learning, as confirmed by comparable escape latencies between genotypes (ANOVA, genotype effect and genotype $\times$ sessions interaction, $p>0.1)$ and $D$-aspartate treatments (ANOVA, treatment effect and treatment $\times$ sessions interaction, $p>0.1$ ), throughout the acquisition phase. Differently from our previous report (Errico et al., 2008a), here we evaluated the spatial mapping formation of mice in two retention tests, resulting from a short (6 trials) and a long (10 trials) training exposure. According to Errico et al. (2008a), after 10 sessions all animals, regardless of genotypes and treatments, presented comparable bias spatial search, as indicated by similar percentage of time spent in the goal quadrant $\left(D d o^{+/+}\right.$, $p<0.05$ at least; $D d o^{-1-}, p<0.05$ at least; $\mathrm{H}_{2} \mathrm{O}, p<0.05$ at least; D-aspartate, $p<0.01$, compared with other quadrants, Fischer's post hoc analysis) (Fig. $6 c, f)$. Conversely, a significant difference in spatial retention was specifically found between genotypes after the short training. Indeed, $D d o^{-1-}$ mice significantly spent more time in the goal quadrant $(p<0.05$ at least, compared with others, Fischer's post hoc analysis), whereas $D d o^{+/+}$animals still exhibited, after six sessions of acquisition, a random spatial search, as indicated by comparable, $\sim 25 \%$, time spent in each quadrant $(p>0.1$, compared with others, Fischer's post hoc analysis) (Fig. 6b). In the pharmacological animal model, after six sessions of training D-aspartate-treated animals showed a selective search preference only for the goal quadrant $(p<0.05$ at least, compared with others, Fischer's post hoc analysis), whereas control group exhibited a bias spatial search not only for the goal but also for the left quadrant $(p<0.05$, compared with right and opposite; $p>0.1$, compared with left, Fischer's post hoc analysis) (Fig. 6e).

e b
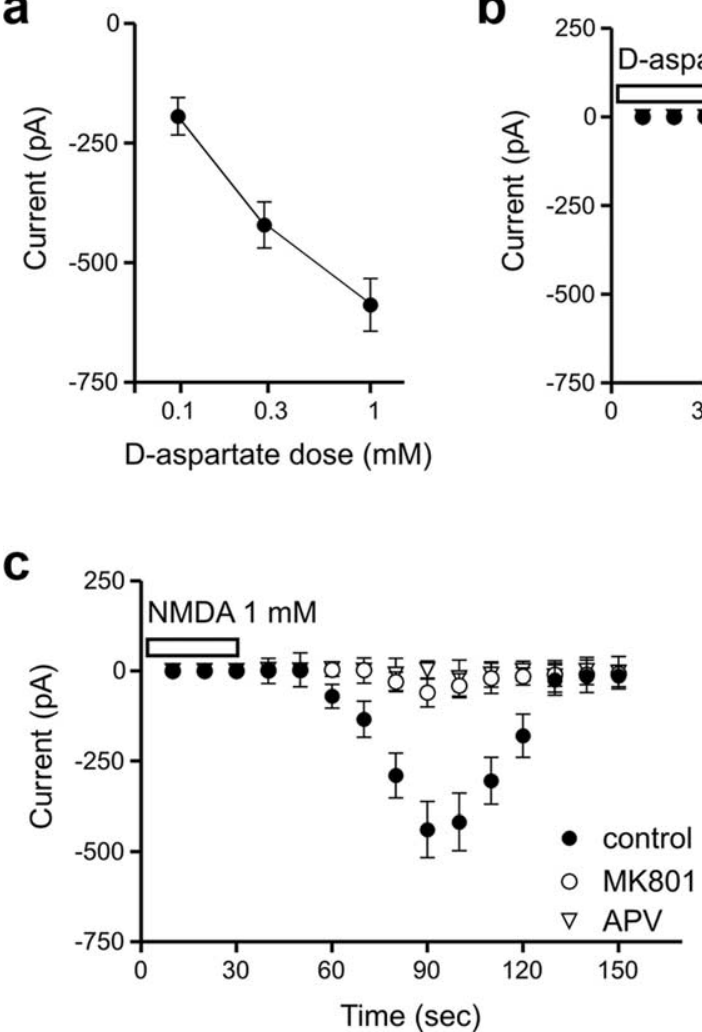

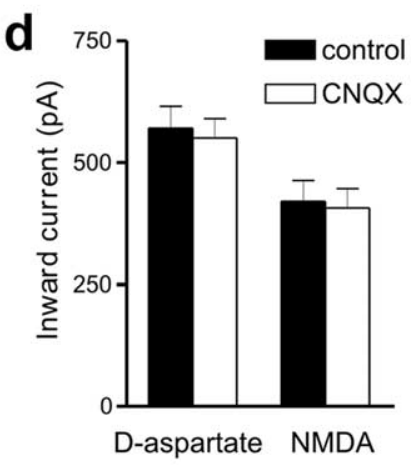

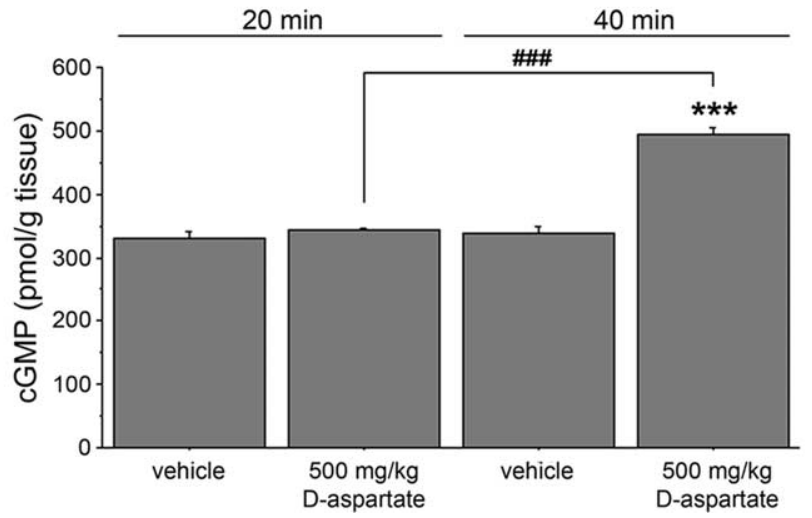

Figure 4. D-Aspartate stimulates NMDARs. $\boldsymbol{a}$, Bath application of $\mathrm{D}$-aspartate $(1 \mathrm{~mm}, 30 \mathrm{~s})$ induced a dose-dependent inward current in striatal neurons. $\boldsymbol{b}, \boldsymbol{c}, \mathrm{D}$-Aspartate-induced inward current was mostly mediated by the activation of NMDARs. Accordingly, preincubation of the slices with MK-801 or APV caused a marked inhibition of D-aspartate-induced current. MK-801 and APV were conversely able to fully block the excitation of striatal neurons mediated by direct application of NMDA. $\boldsymbol{d}$, Blockade of AMPAR by CNQX did not affect D-aspartate or NMDA responses. $\boldsymbol{e}$, NMDAR activity was detected also in vivo by measuring the levels of cerebellar CGMP in C57BL/6J mice injected with $500 \mathrm{mg} / \mathrm{kg}$ D-aspartate or vehicle and killed after 20 ( $n=4$ per treatment) or $40 \mathrm{~min}$ ( $n=4$ per treatment). Acute administration at $40 \mathrm{~min}$ produced a significant increase in cGMP levels. ${ }^{* * *} p<0.0001$, compared with the corresponding vehicle-treated C57BL/6J mice; ${ }^{\# \#} p<0.0001$, compared with 20 min D-aspartate-treated C57BL/6J mice. Values are expressed as mean \pm SEM. Treatments are as indicated.

After 10 training sessions, a similar spatial search was found between treated and untreated mice (Fig. $6 f$ ).

Ddo knock-out mice and D-aspartate-treated mice were also analyzed in a context-dependent fear conditioning paradigm (Shumyatsky et al., 2002). Interestingly, the results obtained using this hippocampus-dependent task indicated a stronger fear response (i.e., freezing behavior) in $D d o^{-1-}$ mice, compared with their wild-type littermates, in the retention test ( $24 \mathrm{~h}$ after the conditioning session) (genotype effect, $p<0.05$, Student's $t$ test) (Fig. $6 g$ ). Conversely, no differences in freezing behavior were 
a

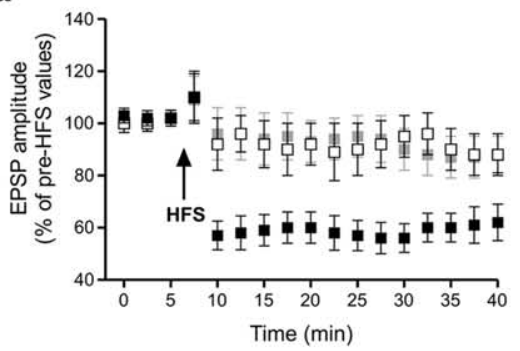

b
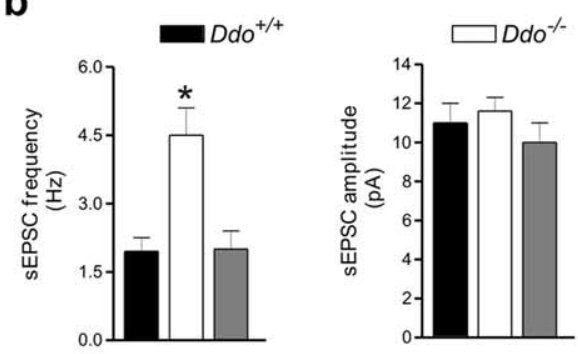

$\mathrm{Ddo}^{+/+}$

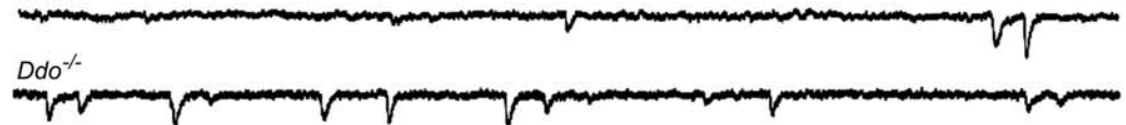

2 months D-aspartate treatment

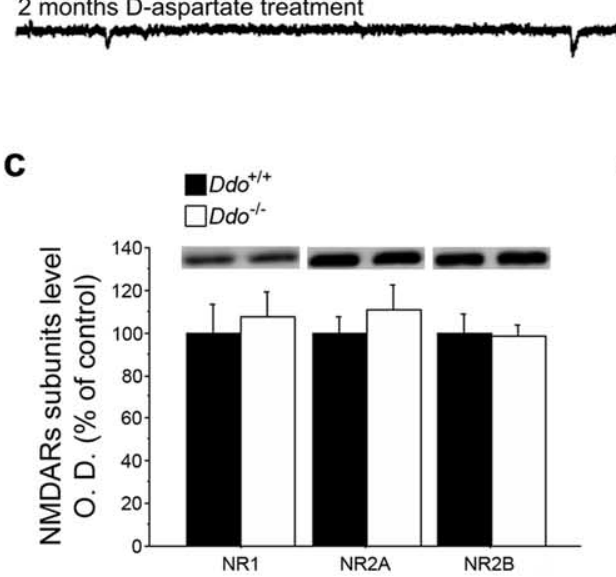

e

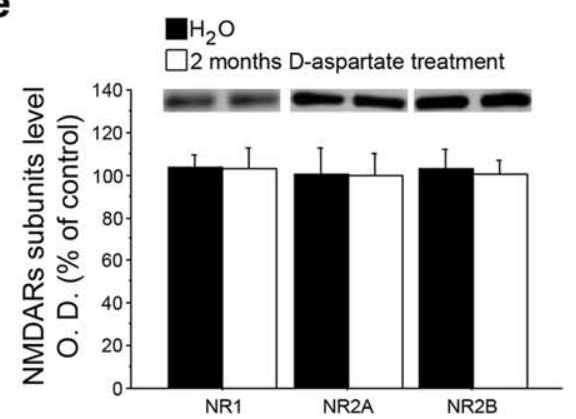

$$
\text { - } D d o^{+/+} \quad \square D d o^{-/}
$$
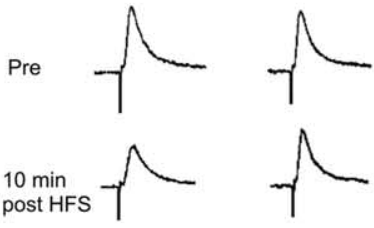

II 2 months

D-aspartate

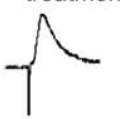

$10 \min$
post HFS

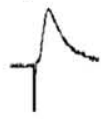

$10 \mathrm{mv}$
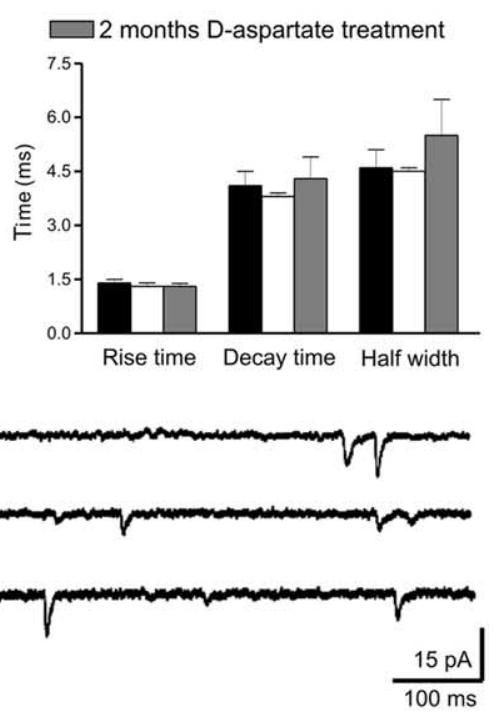

d

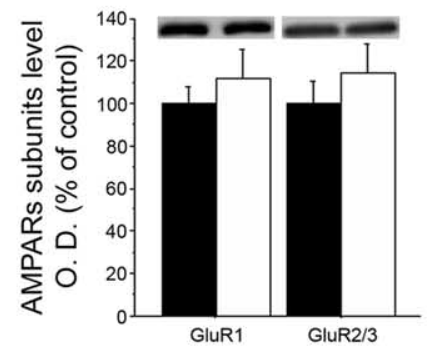

f

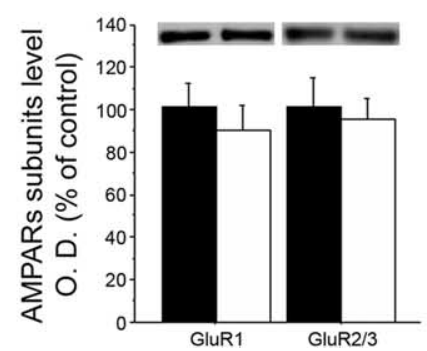

Figure 5. Glutamate transmission and plasticity are altered in striatal neurons from $\mathrm{Ddo}^{-1-}$ mice and in animals chronically exposed to D-aspartate. $\boldsymbol{a}$, The graph shows that corticostriatal LTD was absent in slices from Ddo ${ }^{-1-}$ mice and from mice chronically exposed to D-aspartate. The physiological traces on the right are examples of EPSPs recorded before and after HFS of corticostriatal fibers in slices from $D d 0^{-I-}$ mice, from mice treated with D-aspartate, and from controls. $\boldsymbol{b}$, The frequency of sEPSCs recorded from striatal neurons was significantly enhanced in $D d 0^{-1-}$ striatal neurons. In contrast, amplitude and kinetic properties of $\mathrm{SEPSC} S$ were unaffected by this genetic manipulation. In neurons from mice given chronic $D$-aspartate administration, the properties of sEPSCs were unchanged. Traces below are examples of patch-clamp recordings from single striatal neurons recorded from $D \mathrm{do}^{-1-}$ mice, from mice exposed to $\mathrm{D}$-aspartate in their drinking solution, and from control animals. Altered glutamatergic transmission and plasticity do not derive from a differential expression of glutamate receptors subunits within the detected between genotypes immediately after shock delivery during training session (data not shown). In contrast to mutants, comparable context-dependent freezing responses were recorded in D-aspartate-treated and in control animals, both immediately (data not shown) and $24 \mathrm{~h}$ after conditioning session (treatment effect, $p>0.1$ ) (Fig. 6h).

\section{Discussion}

Although the function of $\mathrm{D}$-aspartate in mammalian brain is still matter of debate, mounting evidence has indicated that this D-amino acid may act as a putative neuromodulator of the glutamatergic system (Schell et al., 1997; Errico et al., 2008a). Here we examined the hypothesis that elevation of $\mathrm{D}$-aspartate concentrations in adult mice might unveil its central influence in behaviors and electrophysiological paradigms associated with NMDAR signaling. To this purpose, we adopted two alternative strategies to generate higher D-aspartate levels in animals: a genetic approach based on the targeted deletion of Ddo gene (Errico et al., 2006) and another based on 2 months of oral administration of this D-amino acid to $\mathrm{C} 57 \mathrm{BL} / 6 \mathrm{~J}$ mice (Errico et al., 2008a).

In line with previous reports (Errico et al., 2006; Huang et al., 2006; Errico et al., 2008a), we detected a strong enhancement of $\mathrm{D}$-aspartate levels in several brain regions, including the striatum, of $D d o^{-1-}$ and $\mathrm{C} 57 \mathrm{BL} / 6 \mathrm{~J}$ treated mice. We also established that such increase did not alter the expression levels of NMDAR and AMPAR subunits. Based on the ability of D-aspartate to act as an agonist at NMDARs, we assessed the functional consequences of increased D-aspartate levels on sensorimotor gating processes. NMDARs are implicated in sensory gating mechanisms, whose alteration is postulated to induce the development of positive symptoms and cognitive fragmentation in obsessive-compulsive disorders and SCZ (Cadenhead et al., 1997). Studies in humans have shown that patients with SCZ have impaired PPI (Braff et al., 1992) and this behavioral paradigm is commonly

striatum of mutants or D-aspartate-treated animals. $\boldsymbol{c}, \boldsymbol{d}$, Indeed Ddo ${ }^{+/+}(n=10)$ and Ddo ${ }^{-/-}(n=10)$ mice display comparable levels of each NMDAR (c) and AMPAR (d) subunit examined. $\boldsymbol{e}$, f, Similarly, D-aspartate administration to (57BL/6J animals produced no significant changes in any of the NMDAR $(\boldsymbol{e})$ or AMPAR (f) subunits ( $n=6$ per treatment). Representative blots comparing the different genotypes or treatments are shown for each protein detected. All values are expressed as mean \pm SEM. Genotypes and treatments are as indicated. 
used in rodents to screen potential psychotic-like or antipsychotic-like properties of new molecules or genes (Geyer et al., 2002). Interestingly, our results indicated that increasing D-aspartate levels in adulthood did not affect basal ASR and PPI. In contrast, D-aspartate attenuated, in both genetic and pharmacological animal models, sensory gating deficits induced by moderate, but not high, doses of MK-801. Such dose-dependent protective effect suggests that D-aspartate may exert a modulatory action in brain areas involved in the processing and filtering of ordered information through its modulation of NMDAR transmission. These results suggest that elevation of glutamatergic signaling, produced by increased $\mathrm{D}$-aspartate levels, could counteract the disruption of gating processes induced by MK-801, resulting in a shift to the right of the dose of NMDAR antagonist required to elicit PPI deficits.

Our results show that increased $\mathrm{D}$-aspartate concentration in the brain is also able to reduce the impairment of PPI produced by AMPH. Behavioral experiments using mutant mice for dopamine receptors indicated a mandatory role of $\mathrm{D}_{2} \mathrm{R}$ in controlling AMPH-induced disruption of PPI (Ralph et al., 1999). Furthermore, previous studies performed in genetically altered mice with a reduction of NMDARs showed enhanced susceptibility to the disruptive effect of AMPH on PPI (Moy et al., 2006). In contrast, GlyT1 heterozygous mice, which are characterized by increased NMDAR transmission (Tsai et al., 2004), showed attenuated sensorimotor gating disturbances in response to AMPH challenge. An intriguing hypothesis to conciliate the present and the abovementioned studies is therefore based on the involvement of a reciprocal antagonistic interaction between NMDAR and $\mathrm{D}_{2} \mathrm{R}$ in the modulation of the disruptive effects produced by AMPH on PPI. In turn, this scenario has an interesting implication, because it suggests a potential common pathway in AMPH-induced PPI disruption that may involve, in addition to dopamine, glutamate transmission.

In line with this possibility, previous electrophysiological studies have shown that genetic inactivation or pharmacological $\mathrm{D}_{2} \mathrm{R}$ blockade upregulates glutamate-mediated transmission in the striatum (Usiello et al., 2000; Centonze et al., 2004a). This effect is mainly achieved through NMDAR-dependent blockade of striatal LTD, a form of synaptic plasticity that causes persistent downregulation of excitatory inputs to this brain area (Centonze et al., 2004a). In light of these observations, our data obtained in $\mathrm{Ddo} \mathrm{o}^{-1-}$ and in D-aspartate-treated mice are strikingly consistent with the idea that D-aspartate-mediated antipsychotic-like effects might be associated with enhancement of glutamate transmission
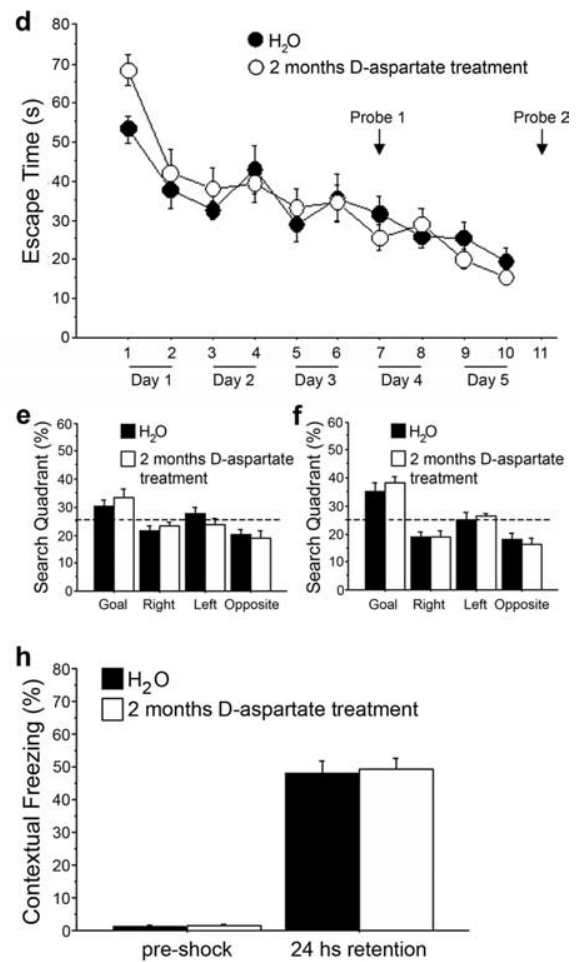

Figure 6. Improved spatial memory in Ddo ${ }^{-1-}$ mice. $a, D d 0^{+/+}(n=11)$ and $D d 0^{-1-}(n=11)$ mice were trained for 5 consecutive days ( 2 sessions/d) in a submerged platform version of the Morris water maze task. Two-way ANOVA, with escape $=1.156 ; p=0.2952)$ and genotype $\times$ days interaction $\left(F_{(9,180)}=0.300 ; p=0.9741\right) \cdot \boldsymbol{b}, \mathrm{A} 60$ s transfer test was performed at day 4 , before the seventh training session (Probe 1 in $\boldsymbol{a}$ ). Whereas $D d 0^{+/+}$mice did not show any preference for the target quadrant ( $p>0.1$, compared with others), $D d 0^{-1-}$ animals spent more time in the goal quadrant $(p<0.05$, compared with right and left; $p<0.01$, compared with opposite). $c$, A second probe test was performed at day 11, at the end of the training phase 0.05 , compared with left; $p<0.01$, compared with right and opposite; Ddo ${ }^{-1-}: p<0.05$, compared with right; $p<0.01$, compared with left and opposite). $\boldsymbol{d}$, Untreated $(n=10)$ and 2 month D-aspartate-treated mice $(n=10)$ were also subjected to showed a significant days effect $\left(F_{(9,162)}=16.295 ; p<0.0001\right)$ but did not display treatment effect $\left(F_{(1,162)}=0.232 ; p=\right.$ $0.6361)$ or treatment $X$ days interaction $\left(F_{(9,162)}=1.218 ; p=0.2876\right) . e$, In the first transfer test, executed before the seventh (Probe 1 in $\boldsymbol{d}$ ), both $\mathrm{H}_{2} \mathrm{O}$ - and D-aspartate-treated mice exhibited a preferential search in the goal quadrant, although untreated animals did not discriminate between the target and the left quadrant $\left(\mathrm{H}_{2} \mathrm{O}: p<0.05\right.$, compared with right and opposite; $p>0.1$, compared with left; D-aspartate: $p<0.05$, compared with left and opposite; $p<0.01$, compared with a targeted search in the goal quadrant $\left(\mathrm{H}_{2} \mathrm{O}: p<0.05\right.$, compared with left and opposite; $p<0.01$, compared with right -aspartate: $p<0.01$, compared with others). Escape time, expressed in seconds, was used as dependent variable in the acquisition phases. Search quadrant, expressed as percentage of time, was used as dependent variable in the probe tests. The dashed lines in $\boldsymbol{b}, \boldsymbol{c}, \boldsymbol{e}$, and $\boldsymbol{f}$ indicate the chance level of search in the four quadrants. ${ }^{*} p<0.05$, compared with $D d 0^{+/+}$mice ( post hoc analysis). $\boldsymbol{g}$, In the contextual fear conditioning task, a significant increase in memory was found, $24 \mathrm{~h}$ after training, in Ddo ${ }^{-1-}$ animals $(n=17)$, compared with Ddo ${ }^{+/+}$littermates $(n=18) . \boldsymbol{h}$, In contrast, D-aspartate administration to $(57 \mathrm{BL} / 6 \mathrm{~J}$ mice did not induce any difference in freezing response between treated $(n=11)$ and untreated $(n=11)$ mice. The percentage of time spent in freezing was used as the dependent variable. ${ }^{*} p<0.05$, compared with Ddo ${ }^{+/+}$mice (Student's $t$ test). All values are expressed as mean \pm SEM. Genotypes and treatments are as indicated.

in the striatum, through the prevention of LTD induction. It should be pointed out that the disruption of LTD produced by genetic or pharmacological elevation of D-aspartate contents does not necessarily involve increased NMDAR signaling. Indeed, the resting membrane potential of striatal neurons was not altered in the two mouse models, and relatively high concentrations of exogenously applied D-aspartate were required to excite striatal neurons. Therefore, many other adaptive processes might occur in $\mathrm{Ddo} \mathrm{o}^{-1-}$ and in D-aspartate-treated mice that could explain our findings, including changes in the activity of dopamine and metabotropic glutamate receptors. Whatever mechanism causes the loss of LTD after chronic D-aspartate elevation, the 
effect of this alteration is an increased glutamatergic drive to striatal neurons. The importance of striatal synaptic adaptations in the antipsychotic action of D-aspartate and of other agents is evident considering that deficits in striatal function produce sensorimotivational disturbances and alter goal-directed behavior in SCZ patients (Swerdlow and Koob, 1987; Goldman-Rakic and Selemon, 1990; Graybiel, 1995, 1997; Calabresi et al., 1997; Canales and Graybiel, 2000). Interestingly, acute administration of D-aspartate to C57BL/6J mice at a dose $(500 \mathrm{mg} / \mathrm{kg})$ able to stimulate NMDARs in vivo failed to attenuate the deficits induced by moderate doses of AMPH or MK-801 (5 and $0.25 \mathrm{mg} / \mathrm{kg}$, respectively) (data not shown). Such findings suggest that the protective effect of this D-amino acid requires its long-term action, during which still-unknown plastic processes along NMDAR signaling cascade may take place. It should also be noted that increased D-aspartate levels did not appear to be implicated in the regulation of ASR. Furthermore, when challenged with AMPH or MK$801, \mathrm{Ddo}^{-1-}$ and $\mathrm{Ddo}{ }^{+/+}$mice displayed comparable motor stimulations. This suggests that deregulated D-aspartate levels do not alter the overall behavioral output elicited by these drugs, but selectively modulate the inhibitory processes involved in gating mechanisms. The basis of such intriguing differential modulation remains so far unclear.

In line with a previous study performed in the hippocampus (Errico et al., 2008a), the ability of D-aspartate to act on NMDARs, has been further demonstrated by electrophysiological experiments in the striatum, which also point out that this D-amino acid does not induce striatal AMPA currents.

In addition, biochemical evaluation of NMDAR-dependent cerebellar cGMP accumulation indicated that, in C57BL/6J mice, acute and chronic administrations of $\mathrm{D}$-aspartate resulted in higher levels of receptor activity. Conversely, no alterations in cerebellar cGMP levels were found in $D d o^{-/-}$mice. Notably, also in $\mathrm{ddY} / \mathrm{DAO}^{-}$mutants, characterized to have higher levels of the endogenous coagonist $\mathrm{D}$-serine, basal in vivo NMDAR activity did not differ from their controls (Almond et al., 2006). To explain this paradox, in line with Almond et al. (2006), we suggest that the absence of DDO since early postnatal developmental stages might result in an overall desensitization of the NMDARnitric-oxide-mediated response.

In addition to displaying the well known positive and negative symptoms, schizophrenic patients are also affected by deficits in virtually all domains of cognitive function, possibly as a result of a NMDAR hypofunctionality (Barch, 2005). In accordance to a role for D-aspartate as a potential antipsychotic molecule, we found a selective enhancement of hippocampus-mediated spatial memory in $D d o^{-1-}$ mice, as revealed by Morris water maze and contextual fear conditioning tasks. Together, these data are in line with those reported for ddY/DAO ${ }^{-}$, GlyT1 mutant, and NR2B transgenic mice, and further support a crucial role for NMDAR activation in the regulation of spatial memory (Tang et al., 1999; Tsai et al., 2004; Maekawa et al., 2005). Although $\mathrm{D}$-aspartate administration induces a substantial enhancement of hippocampal LTP in C57BL/6J mice (Errico et al., 2008), it failed to strongly improve their cognitive functions. This finding may be explained by the influence of this particular genetic background, known to be highly performing in hippocampus-related memory tasks (Nguyen and Gerlai, 2002) and therefore poorly responsive to pharmacological manipulations.

It should be reported that a previous work using another $D d o$ knock-out line indicated an opposite effect of increased brain levels of D-aspartate on sensorimotor gating modulation (Weil et al., 2006). The reasons of these conflicting results are still elusive.
However, differences in breeding strategies and/or in genetic background may account as possible factors to explain such discrepancies.

In conclusion, the present work supports a central neuromodulatory role for D-aspartate and provides, for the first time, evidence that increased levels of this molecule may have beneficial effects in treating SCZ. It should be noted that persistent NMDAR activation triggers excitotoxic processes. Although $D d o^{-/-}$animals showed a lifespan comparable to their $\mathrm{Ddo} o^{+/+}$ littermates, future studies are necessary to determine the existence of possible side effects associated with a long-term D-aspartate exposure.

\section{References}

Almond SL, Fradley RL, Armstrong EJ, Heavens RB, Rutter AR, Newman RJ, Chiu CS, Konno R, Hutson PH, Brandon NJ (2006) Behavioral and biochemical characterization of a mutant mouse strain lacking D-amino acid oxidase activity and its implications for schizophrenia. Mol Cell Neurosci 32:324-334.

Barch DM (2005) The cognitive neuroscience of schizophrenia. Annu Rev Clin Psychol 1:321-353.

Braff DL, Grillon C, Geyer MA (1992) Gating and habituation of the startle reflex in schizophrenic patients. Arch Gen Psychiatry 49:206-215.

Braff DL, Geyer MA, Swerdlow NR (2001) Human studies of prepulse inhibition of startle: normal subjects, patient groups, and pharmacological studies. Psychopharmacology 156:234-258.

Cadenhead KS, Geyer MA, Butler RW, Perry W, Sprock J, Braff DL (1997) Information processing deficits of schizophrenia patients: relationship to clinical ratings, gender and medication status. Schizophr Res 28:51-62.

Calabresi P, Pisani A, Mercuri NB, Bernardi G (1992) Long-term potentiation in the striatum is unmasked by removing the voltage-dependent magnesium block of NMDA receptor channels. Eur J Neurosci 4:929-935.

Calabresi P, De Murtas M, Bernardi G (1997) The neostriatum beyond the motor function: experimental and clinical evidence. Neuroscience 78:39-60.

Canales JJ, Graybiel AM (2000) A measure of striatal function predicts motor stereotypy. Nat Neurosci 3:377-383.

Centonze D, Usiello A, Costa C, Picconi B, Erbs E, Bernardi G, Borrelli E, Calabresi P (2004a) Chronic haloperidol promotes corticostriatal longterm potentiation by targeting dopamine D2L receptors. J Neurosci 24:8214-8222.

Centonze D, Gubellini P, Usiello A, Rossi S, Tscherter A, Bracci E, Erbs E, Tognazzi N, Bernardi G, Pisani A, Calabresi P, Borrelli E (2004b) Differential contribution of dopamine D2S and D2L receptors in the modulation of glutamate and GABA transmission in the striatum. Neuroscience 129:157-166.

Cepeda C, Hurst RS, Altemus KL, Flores-Hernández J, Calvert CR, Jokel ES, Grandy DK, Low MJ, Rubinstein M, Ariano MA, Levine MS (2001) Facilitated glutamatergic transmission in the striatum of D2 dopamine receptor-deficient mice. J Neurophysiol 85:659-670.

Curzon P, Decker MW (1998) Effects of phencyclidine (PCP) and (+)MK801 on sensorimotor gating in CD-1 mice. Prog Neuropsychopharmacol Biol Psychiatry 22:129-146.

D’Aniello A, Di Fiore MM, Fisher GH, Milone A, Seleni A, D’Aniello S, Perna AF, Ingrosso D (2000) Occurrence of D-aspartic acid and N-methyl-Daspartic acid in rat neuroendocrine tissues and their role in the modulation of luteinizing hormone and growth hormone release. FASEB J 14:699-714.

Errico F, Pirro MT, Affuso A, Spinelli P, De Felice M, D’Aniello A, Di Lauro R (2006) A physiological mechanism to regulate D-aspartic acid and NMDA levels in mammals revealed by $\mathrm{D}$-aspartate oxidase deficient mice. Gene 374:50-57.

Errico F, Nisticò R, Palma G, Federici M, Affuso A, Brilli E, Topo E, Centonze D, Bernardi G, Bozzi Y, D’Aniello A, Di Lauro R, Mercuri NB, Usiello A (2008a) Increased levels of d-aspartate in the hippocampus enhance LTP but do not facilitate cognitive flexibility. Mol Cell Neurosci 37:236-246.

Errico F, Santini E, Migliarini S, Borgkvist A, Centonze D, Nasti V, Carta M, De Chiara V, Prosperetti C, Spano D, Herve D, Pasqualetti M, Di Lauro R, Fisone G, Usiello A (2008b) The GTP-binding protein Rhes modulates 
dopamine signalling in striatal medium spiny neurons. Mol Cell Neurosci 37:335-345.

Geyer MA, Mcllwain KL, Paylor R (2002) Mouse genetic models for prepulse inhibition: an early review. Mol Psychiatry 7:1039-1053.

Goldman-Rakic PS, Selemon LD (1990) New frontiers in basal ganglia research. Introduction. Trends Neurosci 13:241-244.

González-Maeso J, Ang RL, Yuen T, Chan P, Weisstaub NV, López-Giménez JF, Zhou M, Okawa Y, Callado LF, Milligan G, Gingrich JA, Filizola M, Meana JJ, Sealfon SC (2008) Identification of a serotonin/glutamate receptor complex implicated in psychosis. Nature 452:93-97.

Graybiel AM (1995) Building action repertoires: memory and learning functions of the basal ganglia. Curr Opin Neurobiol 5:733-741.

Graybiel AM (1997) The basal ganglia and cognitive pattern generators. Schizophr Bull 23:459-469.

Huang AS, Beigneux A, Weil ZM, Kim PM, Molliver ME, Blackshaw S, Nelson RJ, Young SG, Snyder SH (2006) D-Aspartate regulates melanocortin formation and function: behavioral alterations in D-aspartate oxidasedeficient mice. J Neurosci 26:2814-2819.

Javitt DC, Zukin SR (1991) Recent advances in the phencyclidine model of schizophrenia. Am J Psychiatry 148:1301-1308.

Kristiansen LV, Huerta I, Beneyto M, Meador-Woodruff JH (2007) NMDA receptors and schizophrenia. Curr Opin Pharmacol 7:48-55.

Lynch MA (2004) Long-term potentiation and memory. Physiol Rev 84:87-136.

Maekawa M, Watanabe M, Yamaguchi S, Konno R, Hori Y (2005) Spatial learning and long-term potentiation of mutant mice lacking D-aminoacid oxidase. Neurosci Res 53:34-38.

Mansbach RS, Geyer MA, Braff DL (1988) Dopaminergic stimulation disrupts sensorimotor gating in the rat. Psychopharmacology 94:507-514.

Martineau M, Baux G, Mothet JP (2006) D-serine signalling in the brain: friend and foe. Trends Neurosci 29:481-491.

Moy SS, Perez A, Koller BH, Duncan GE (2006) Amphetamine-induced disruption of prepulse inhibition in mice with reduced NMDA receptor function. Brain Res 1089:186-194.

Nguyen PV, Gerlai R (2002) Behavioural and physiological characterization of inbred mouse strains: prospects for elucidating the molecular mechanisms of mammalian learning and memory. Genes Brain Behav 1:72-81.

Olney JW, Farber NB (1995) NMDA antagonists as neurotherapeutic drugs, psychotogens, neurotoxins, and research tools for studying schizophrenia. Neuropsychopharmacology 13:335-345.

Paylor R, Crawley JN (1997) Inbred strain differences in prepulse inhibition of the mouse startle response. Psychopharmacology 132:169-180.

Ralph RJ, Varty GB, Kelly MA, Wang YM, Caron MG, Rubinstein M, Grandy DK, Low MJ, Geyer MA (1999) The dopamine $\mathrm{D}_{2}$, but not $\mathrm{D}_{3}$ or $\mathrm{D}_{4}$, receptor subtype is essential for the disruption of prepulse inhibition produced by amphetamine in mice. J Neurosci 19:4627-4633.

Sawa A, Snyder SH (2002) Schizophrenia: diverse approaches to a complex disease. Science 296:692-695.
Schell MJ, Molliver ME, Snyder SH (1995) D-serine, an endogenous synaptic modulator: localization to astrocytes and glutamate-stimulated release. Proc Natl Acad Sci U S A 92:3948-3952.

Schell MJ, Cooper OB, Snyder SH (1997) D-aspartate localizations imply neuronal and neuroendocrine roles. Proc Natl Acad Sci USA 94:2013-2018.

Shumyatsky GP, Tsvetkov E, Malleret G, Vronskaya S, Hatton M, Hampton L, Battey JF, Dulac C, Kandel ER, Bolshakov VY (2002) Identification of a signaling network in lateral nucleus of amygdala important for inhibiting memory specifically related to learned fear. Cell 111:905-918.

Silva A, Simpson E, Takahashi J, Lipp H, Nakanishi S, Wehner J, Giese K, Tully T, Abel T, Chapman P (1997) Mutant mice and neuroscience: recommendations concerning genetic background. Banbury Conference on genetic background in mice. Neuron 19:755-759.

Snyder SH (1976) The dopamine hypothesis of schizophrenia: focus on the dopamine receptor. Am J Psychiatry 133:197-202.

Swerdlow NR, Koob GF (1987) Lesions of the dorsomedial nucleus of the thalamus, medial prefrontal cortex and pedunculopontine nucleus: effects on locomotor activity mediated by nucleus accumbens-ventral pallidal circuitry. Brain Res 412:233-243.

Swerdlow NR, Braff DL, Geyer MA (2000) Animal models of deficient sensorimotor gating: what we know, what we think we know, and what we hope to know soon. Behav Pharmacol 11:185-204.

Tang K, Low MJ, Grandy DK, Lovinger DM (2001) Dopamine-dependent synaptic plasticity in striatum during in vivo development. Proc Natl Acad Sci U S A 98:1255-1260.

Tang YP, Shimizu E, Dube GR, Rampon C, Kerchner GA, Zhuo M, Liu G, Tsien JZ (1999) Genetic enhancement of learning and memory in mice. Nature 401:63-69.

Tsai G, Coyle JT (2002) Glutamatergic mechanisms in schizophrenia. Annu Rev Pharmacol Toxicol 42:165-179.

Tsai G, Ralph-Williams RJ, Martina M, Bergeron R, Berger-Sweeney J, Dunham KS, Jiang Z, Caine SB, Coyle JT (2004) Gene knockout of glycine transporter 1: characterization of the behavioral phenotype. Proc Natl Acad Sci U S A 101:8485-8490.

Tsai GE, Yang P, Chung LC, Tsai IC, Tsai CW, Coyle JT (1999) D-serine added to clozapine for the treatment of schizophrenia. Am J Psychiatry 156:1822-1825.

Usiello A, Baik JH, Rougé-Pont F, Picetti R, Dierich A, LeMeur M, Piazza PV, Borrelli E (2000) Distinct functions of the two isoforms of dopamine D2 receptors. Nature 408:199-203.

Weil ZM, Huang AS, Beigneux A, Kim PM, Molliver ME, Blackshaw S, Young SG, Nelson RJ, Snyder SH (2006) Behavioural alterations in male mice lacking the gene for D-aspartate oxidase. Behav Brain Res 171:295-302.

Wood PL, Emmett MR, Wood JA (1994) Involvement of granule, basket and stellate neurons but not Purkinje or Golgi cells in cerebellar cGMP increases in vivo. Life Sci 54:615-620. 